\title{
Optimization of Hybrid Renewable Energy System Using Homer
}

\author{
D.Suchitra, R.Rajarajeswari, Joydeep Dasgupta
}

\begin{abstract}
In this modern epoch Sustainable Energy Resources (SER) takes an upper hand in meeting the rise in power demand. Over the last few years, the increasing electrical power demand has prompted an incredible need for power from sustainable energy sources. The irradiation from solar, wind turbines are pondered as the main source of power generation since they supplement one another. For the general development of the economy, it is important that the agro-based economy would lead to the growth of the country. It is neither achievable nor affordable to dispatch power in the far away locales for a scarcely populated town. In this paper, the supplanting of energy sources with the sustainable power sources utilizing HOMER programming is performed. An independent sustainable power sources (ISPS) is used to meet the load and the cost is evaluated. The work is performed for real time data under different schemes like $P V$, wind and its combination. The optimization of operating cost under two scenario of using the ISPS (either PV or Wind) and using both PV \& wind for real-time input taken from Sicud village in Philippines and Laboratory load data of SRMIST in India is performed. The comparison of the operating cost for the two region under two cases is executed and analyzed.
\end{abstract}

\section{INTRODUCTION}

Conventional Resources like coal and other fossil energy sources are draining year by year. As there is a rise in power demand day by day because of increment in the world's population and modernization; these sources does not appear to be equipped for satisfying the future demand of the world. Besides; they are the real reason for $\mathrm{CO} 2$ and emission of Green House Gas (GHG). Almost two-third of the world's population is releasing $\mathrm{CO}_{2}$ as per the survey. Due to the usage of petrol and diesel based transports and the heat emission due to the electrically powered system contributes around $42 \%$ of worldwide $\mathrm{C} 02$ discharge. Numerous countries in Europe like the UK are focused on diminishing the $\mathrm{C} 02$ discharges up to $80 \%$ by 2050 when contrasted with 1990 emanation levels. This is accomplished by expanding the offer of sustainable sources in the generation of energy.

In the ongoing years; many research has undergone in the arena of SER and Distributed Generation frameworks (DGF). Amid the SER, because of ubiquitous nature and wide accessibility, the solar cells and wind energy frameworks are generally utilized. But these SERs are climate reliant and sporadic in nature. In addition; the DGs has numerous points of interest over the customary generation framework. DG lessens the losses due to the transmission which can spare the cost up to $10-15 \%$. Also, DG is significantly vulnerable to power disruption on a large scale caused because of regular or artificial debacles or just because of concurrent failure of different generators in a local grid. Above all; it decreases GHG emanation. A Microgrid (MG) containing different DGs can deliver power to load in a small town when contrasted with the macro grid. This MG may work in an independent framework or in a grid associated system. The blend of solar and wind energy sources alongside with different sources in a MG framework can form an optimal fusion which can subdue the issue identified which relies on climatic condition and unconventionality while fulfilling the load demand; lessening emanation and making the entire framework financially savvy.

Voluminous research work has been carried out in the field of SER along with future developmental aspects. A brief introduction on the SER system along with the survey on technologies of the framework and its economic compactness was explained by authors in [1] and [2]. Salehin et al., [3] suggested optimization of a renewable energy based hybrid framework for a small town at Kuakata in Bangladesh. The generating and storage devices considered for the work were PV, Wind, Diesel generator and battery system. Sensitivity analysis was also carried out. Optimization of distributed generation framework to yield low cost for generation using HOMER was analyzed in [4],[5],[6] and [9]. A comparison of the Integrated Power System and PV system on economical and natural impact was proposed by Alam et al., in [8]. The optimization of a cost effective, reliable SERs for a remote beach locale in Bangladesh was proposed in [10] considering the selection of generating devices and the sizing of units . Olly roy Chowdary et al., [11] proposed an optimal structuring of a Hybrid framework (HF) with solar PV and wind turbine for a seaward zone close to Suncheon situvated at South Korea. Vikas Khare et al., in [12] examined the load pattern of Cop control zone at Sagar in India and demonstrated an optimization model using PSO and Chaotic PSO programming. An analysis on the difficulties and solutions of HF was proposed by Rashid Al Badwawi et al., in [13]. Electrical demand calculation and optimization of $\mathrm{HF}$ for a technical institute in Kota, India was proposed in [14].
Revised Version Manuscript Received on 10 September, 2019.

D.Suchitra, SRM Institute Of Science and Technology, Kattankulathur, Tamilnadu, India.(Email: such1978@yahoo.com)

R.Rajarajeswari, SRM Institute Of Science and Technology, Kattankulathur, Tamilnadu, India.

Joydeep Dasgupta, SRM Institute Of Science and Technology, Kattankulathur, Tamilnadu, India. 


\section{OPTIMIZATION OF HYBRID RENEWABLE ENERGY SYSTEM USING HOMER}

\section{COST OPTIMIZATION}

\section{Present Cost Calculation in Homer}

The total existing cost incurred for the span cycle of the componenet is calculated as the present estimation of all the expensesincluded for installation and making the component work for life span minus the present estimation of the incomes that it acquires over the venture lifetime. HOMER figures the total existing expense of every component in the framework .

Sample: A diesel generator has an underlying capital expense of $96,000 \$$, a substitution cost of $48,000 \$$, and a lif span of 3.52 years. Its expense for operation and maintenance $(\mathrm{O} \& \mathrm{M})$ is 2,471 \$/yr. what's more, its fuel cost are $\$ 34,969 / y r$. Inorder to calculate the total existing cost of a generator over 25 years at a yearly discount of $6 \%$, HOMER delivers a Cash Flow table. The capital expense happens toward the beginning of the undertaking. The yearly O\&M and fuel costs happen toward the finish of every year. The cost and the net present expense contrast just in sign, so the total existing expense of this generator over the 25-year venture lifetime is $\$ 725,240$.

\section{Operating Cost}

The operating cost is the yearly expenses included for the working of the system that includes revenues except the given as

$$
\begin{aligned}
& C_{\text {oper }}=C_{\text {annual,total }}-C_{\text {annual,cap }} \\
& \text { Where, } \\
& C_{\text {oper }} \text {-The operating cost of the system in } \$ / \mathrm{yr} \\
& C_{\text {annual,total }} \text { - The total annualized cost in } \$ / \mathrm{yr} \\
& \mathrm{C}_{\text {annual,cap }} \text {-The total annualized capital cost }
\end{aligned}
$$

\section{OPTIMIZATION FOR LOAD DATA OF SICUD IN PALAWAN USING HOMER}

This work is to investigate the choices for giving power to Sicud a little town in Palawan, Philippines by utilizing wind, solar PV or diesel generation. The outcomes demonstrate the effect of various presumption about the wind asset, fuel cost, and the reliability of the framework. The figure 1 depicts the location of the village.

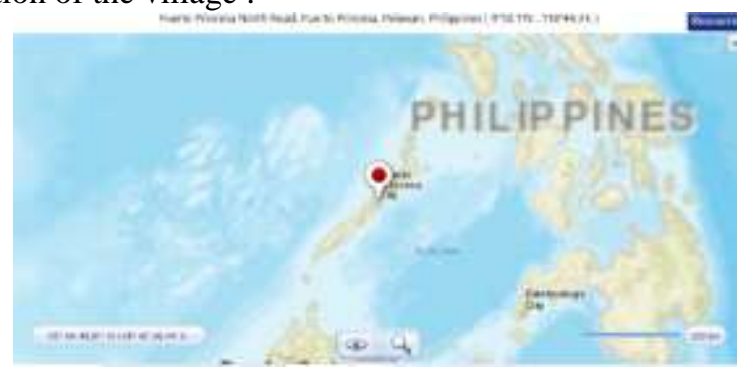

Fig 1. location of site

\subsection{Renewable Source DATA}

\section{Solar source Data}

Figure 2 portraits the solar data from HOMER. The daily radiation is maximum in March, which is given as 5.988 $\mathrm{kW} / \mathrm{m}^{2} /$ day and minimum during September, which is 4.296 $\mathrm{kW} / \mathrm{m}^{2}$ per day. The average solar irradiation available for a year on a day basis is $4.87 \mathrm{~kW} / \mathrm{m}^{2}$. substitution costs happen each 3.52 years. The total existing capital investment cost. The operating cost (HOMER) is

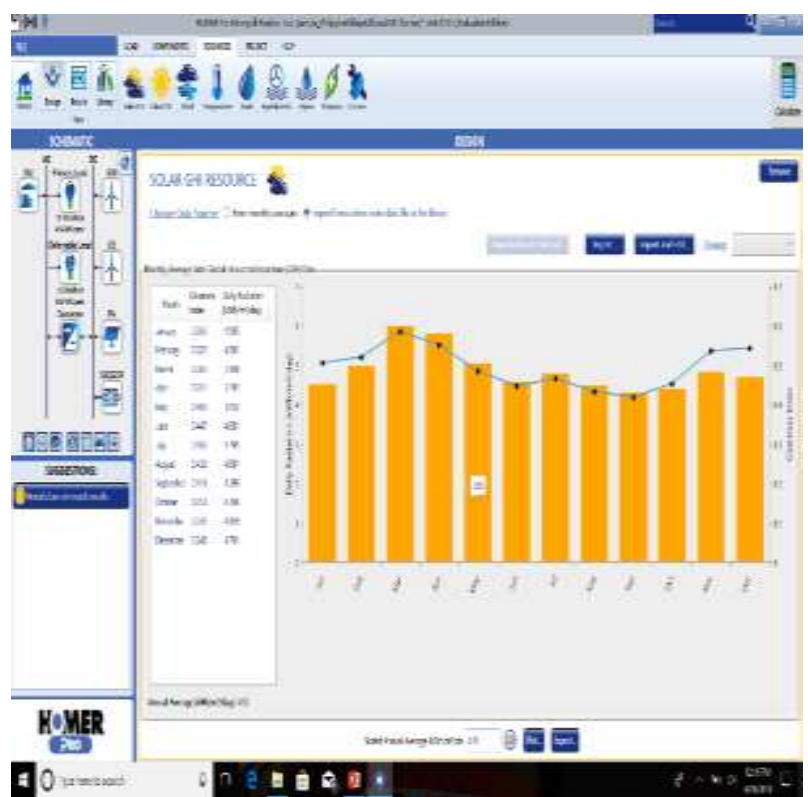

Fig 2. Solar GHI resource

\section{Wind Data}

The wind resource statistics were created utilizing HOMER's wind information generator. The day to day wind profile depends on one day estimations taken in nearby area. Other parameters are considered standard for the area.The wind file used in this analysis is based on inadequate wind data. Better wind data should be obtained before proceeding further. Figure 3 depicts the wind resources considered using HOMER software.

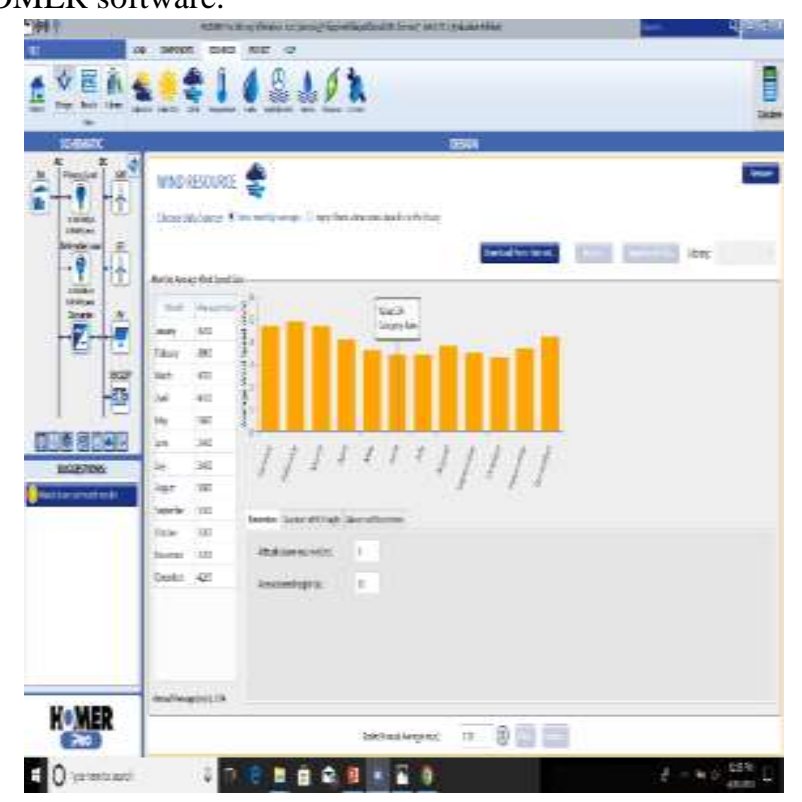

Fig 3. Wind Resource

\section{Load}

Daily load profile depends on educated conjucture of peak and base load for residential consumer. Generally, for a small residential the load demand are peak from 4 to $5 \mathrm{Pm}$ till night. It is critical to endeavor to obtain good measurement of the peak demand, since this will influence the increase or decrease in size of the generator and inverter. Figure 4 gives theelectric load data for a year.

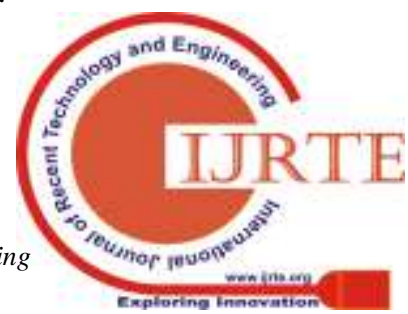




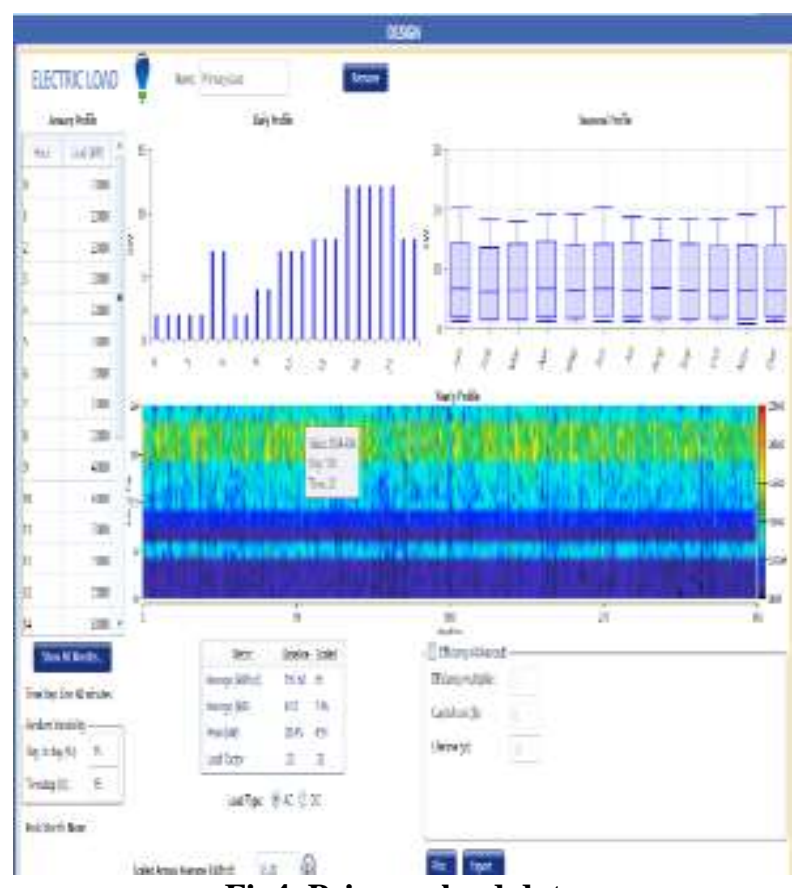

Fig4. Primary load data

\subsection{Sustainable Source}

\section{PV system}

The PV panel with the selection of reflector and the irradiation level along with the cost is shown in figure 8 . Price and lifetime of the PV system are based on feasibility report.Performance based data are commonly used as defaults.

\section{Wind Turbine}

The wind file is generated using HOMER's on daily basis. The selection of wind turbine along with the wind speed and output power are focused in figure 6 .

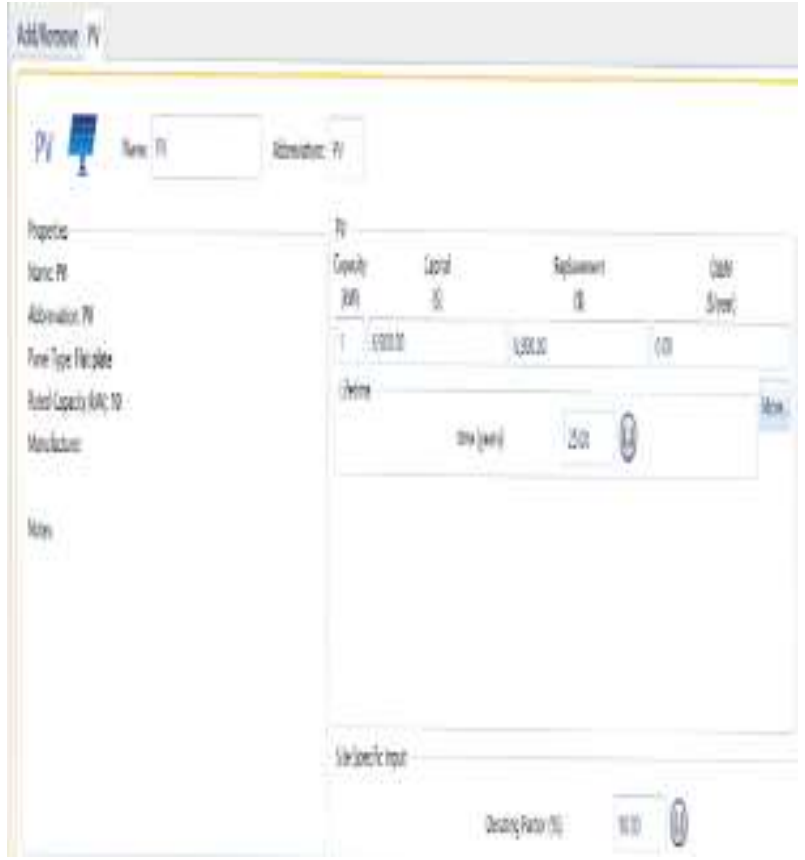

Fig5. -PV panel

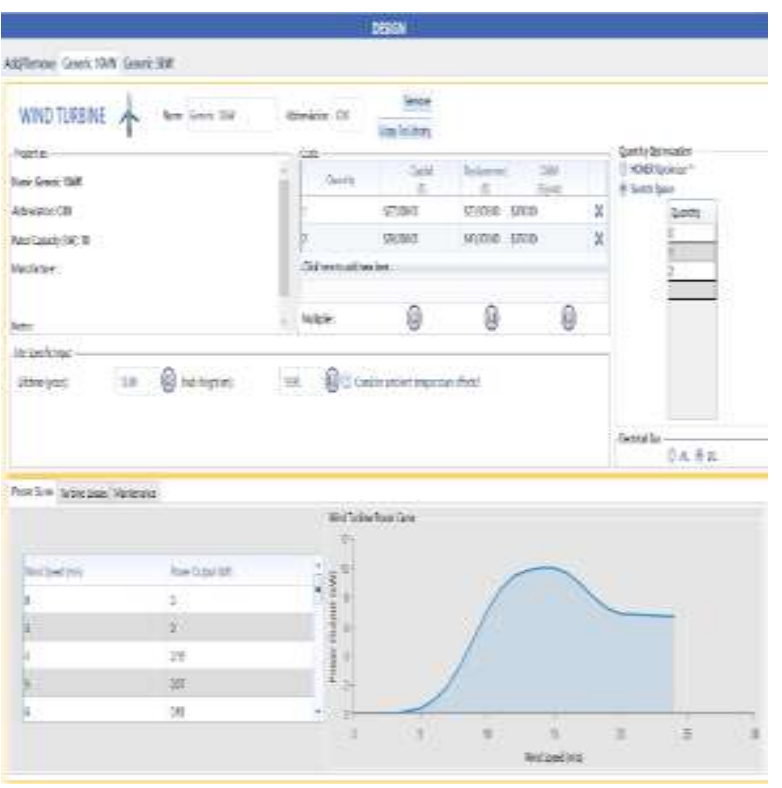

Fig 6. Wind Turbine

\section{3.Generator}

The cost and data considering performance of Diesel Generator(DG) rely on the standard values which is utilized by experts. Owing to the accountability of auxiliary devices like fuel tank and controllers etc the replacement cost of the DG is around $20 \%$ lesser to the initial cost of the system.

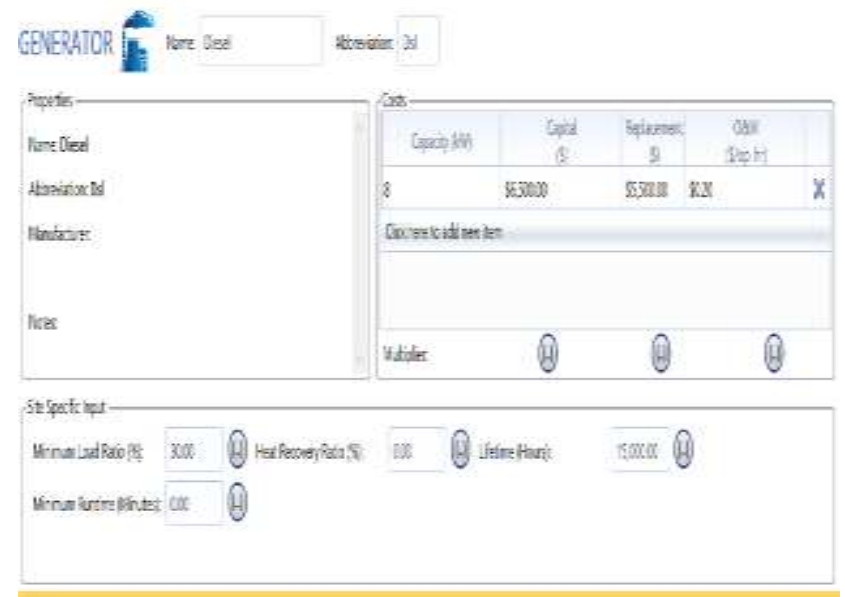

Fig 7. Diesel Generator data in HOMER

For this size of load demand given on the stsstem, the least cost framework commonly incorporates a non-renewable energy source generator. A zero size is incorporated so that all SER would be included in HOMER. DGs general design practice makes it to be seized for the foreseen load. For the case study considering load at Sicud village, $4.5 \mathrm{~kW}$ of peak load is substituted for the DG of rating $5 \mathrm{~kW}$. Figure 7 gives the DG used for this wok.

\section{Batteries}

Battery information given in the feasibility report was contradictory. Assumed the use of "marine" batteries are considered . $20 \%$ added to initial cost to account for purchase of wires, racks, etc. that do not need replacing when batteries are out. Figure 8 depicts the HOMER battery model. 


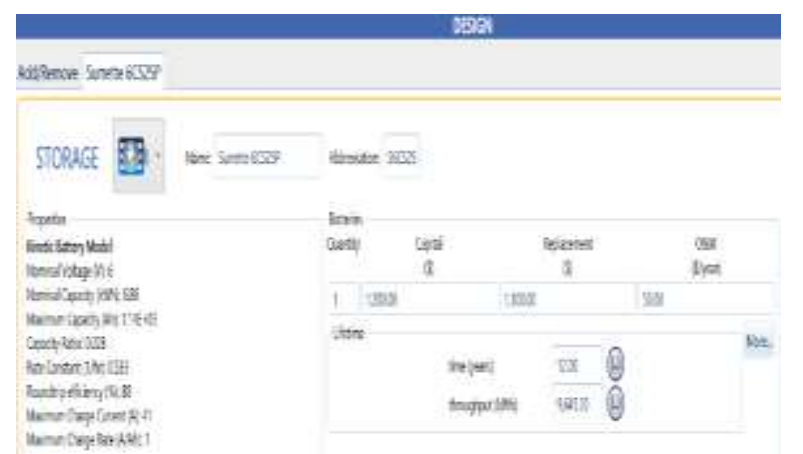

Fig 8. Battery model in HOMER

\section{Converter}

Any framework that contains both $\mathrm{AC}$ and $\mathrm{DC}$ components needs a converter section. The Converter in HOMER enables to characterize the expenses of the converter andalso determines the specifications of an inverter and rectifier parameters.
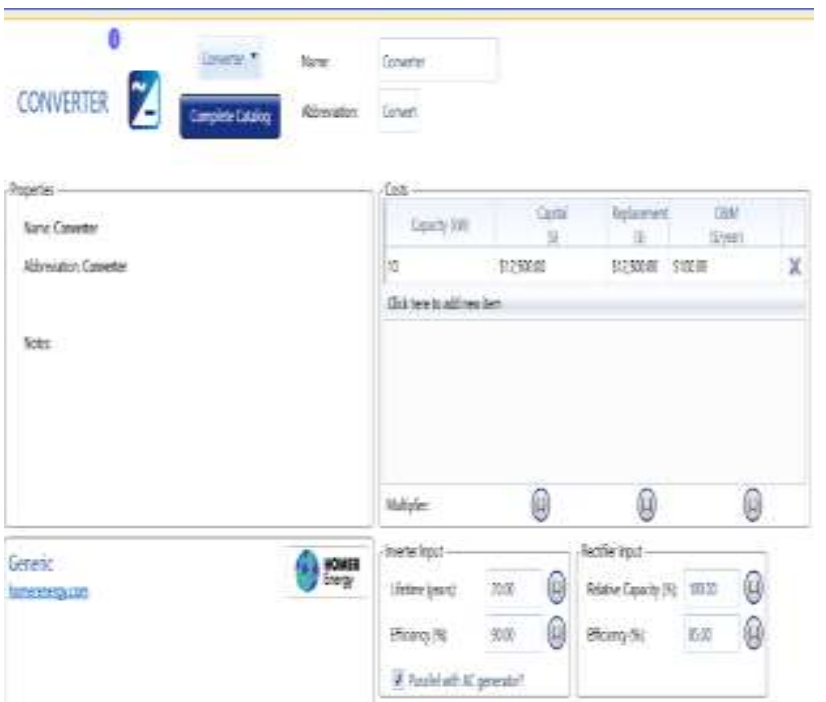

Fig 9. Converter in HOMER

The Costs table incorporates the underlying capital expense and cost incurred for replacement of devices and O\&M costs. In the Costs table of the converter in HOMER page , entery of curve for converter cost can be made i.e., the manner in which the expense fluctuates with size.

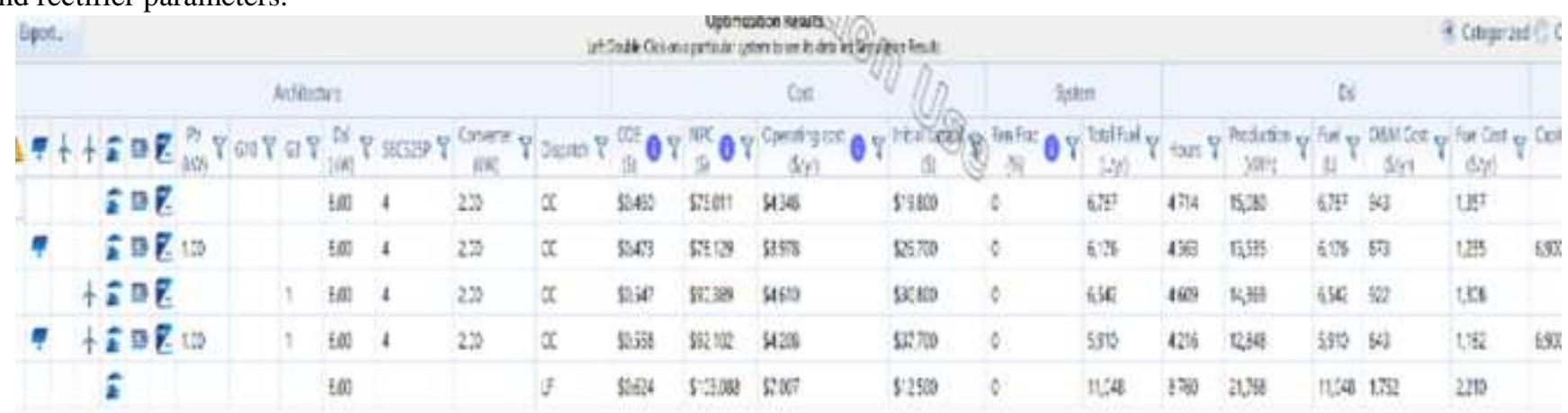

Fig10. Optimized Results for the case study of Sicud village

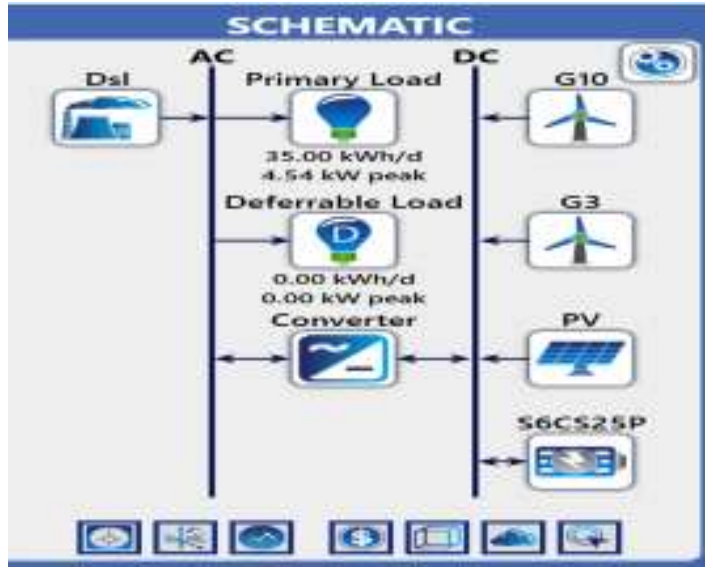

Fig 11 Schematic diagram of the system considered for Case-A in HOMER

The optimization for the cost minimization is performed using HOMER for the Sicud village and the tabulation of O\&M cost, Fuel cost and capital cost is shown in Fig11 and the Fig 10 depicts theschematic diagram of the system considered for serving the load demand from the small town considered in Sicud village.

\section{OPTIMIZATION FOR LOAD DATA OF SRMIST LAB}

The real time load data taken from SRMIST ,India is considered for the optimization and O\&M ,fuel and total Present cost are calculated .Using homer software the optimization for one of the lab load is performed. Figure 12 depicts the location of the lab in SRMIST, India. 


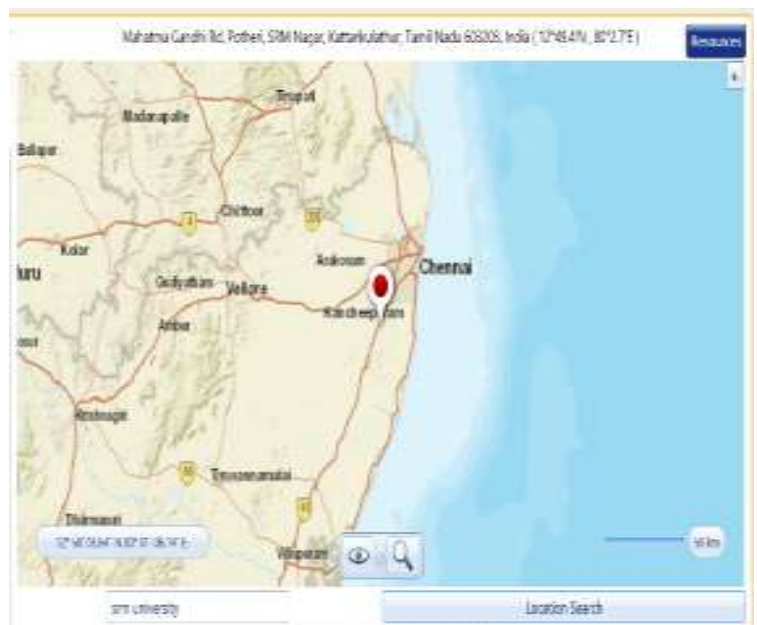

Fig.12 Location site of SRMIST

SRM lab consists of 4 fans, 4 lights, each fan has rating of $75 \mathrm{Wh}$ total rating of 4 fans is $300 \mathrm{Wh}$ and each light have rating of $56 \mathrm{Wh}$ so total rating of 4 lights is $224 \mathrm{Wh}$. The total power consumed by the lab is $524 \mathrm{Wh}$. The simulation of one of the SRM lab is carried out to analysis and determine whether the usage of grid power can be reduced using the renewable hybrid energy source

\subsection{Resource Data Simulation Of Srmist Lab ( Pv Panel)}

\section{Solar Resource}

Solar GHI resource bar diagram is shown in figure 13, here the solar data given are downloaded from the NASA. It is inferred that the highest radiation is during the month of March due to summer. The radiation during March is $6.760 \mathrm{kWh} / \mathrm{m}^{2} /$ day. The lowest radiation is during the month of November i.e.; $4.050 \mathrm{kWh} / \mathrm{m}^{2} /$ day. The annual average radiation is $5.37 \mathrm{kWh} / \mathrm{m}^{2} / \mathrm{day}$.

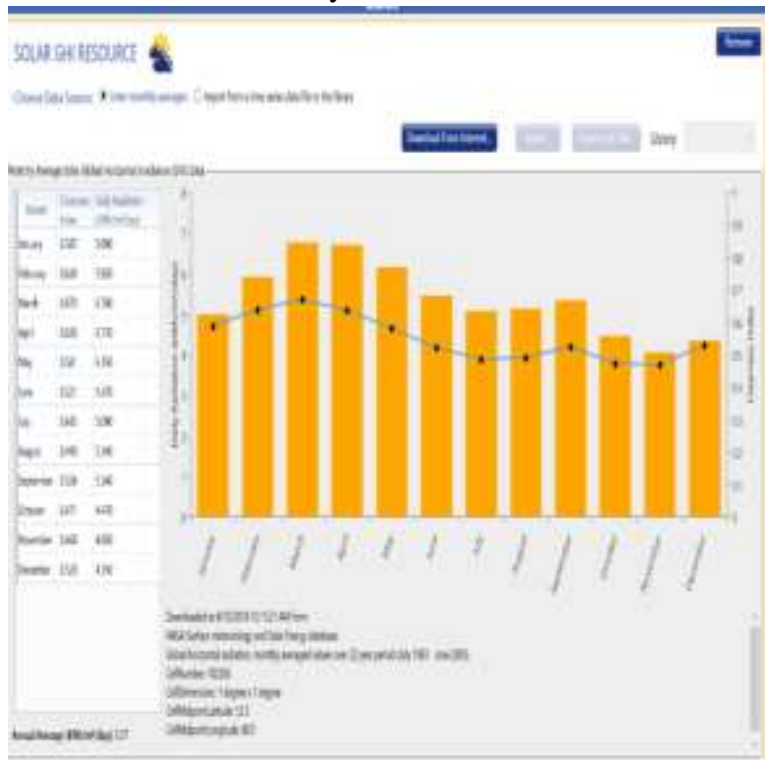

Fig 13. Solar GHI resource

\section{Load Profile}

As specified earlier the load curve considered for a day is based on technical assumption as per standards. Generally, the load is found maximum during morning 8.00AM to $4: 30 \mathrm{PM}$ i.e the duration of the lab conduction. The size consideration for inverter and generator will be more if there is a maximum peak duration so, best estimate during peak hour has to be performed. Figure 14 and 15 gives a detail account on electric load data considered in case B analysis.

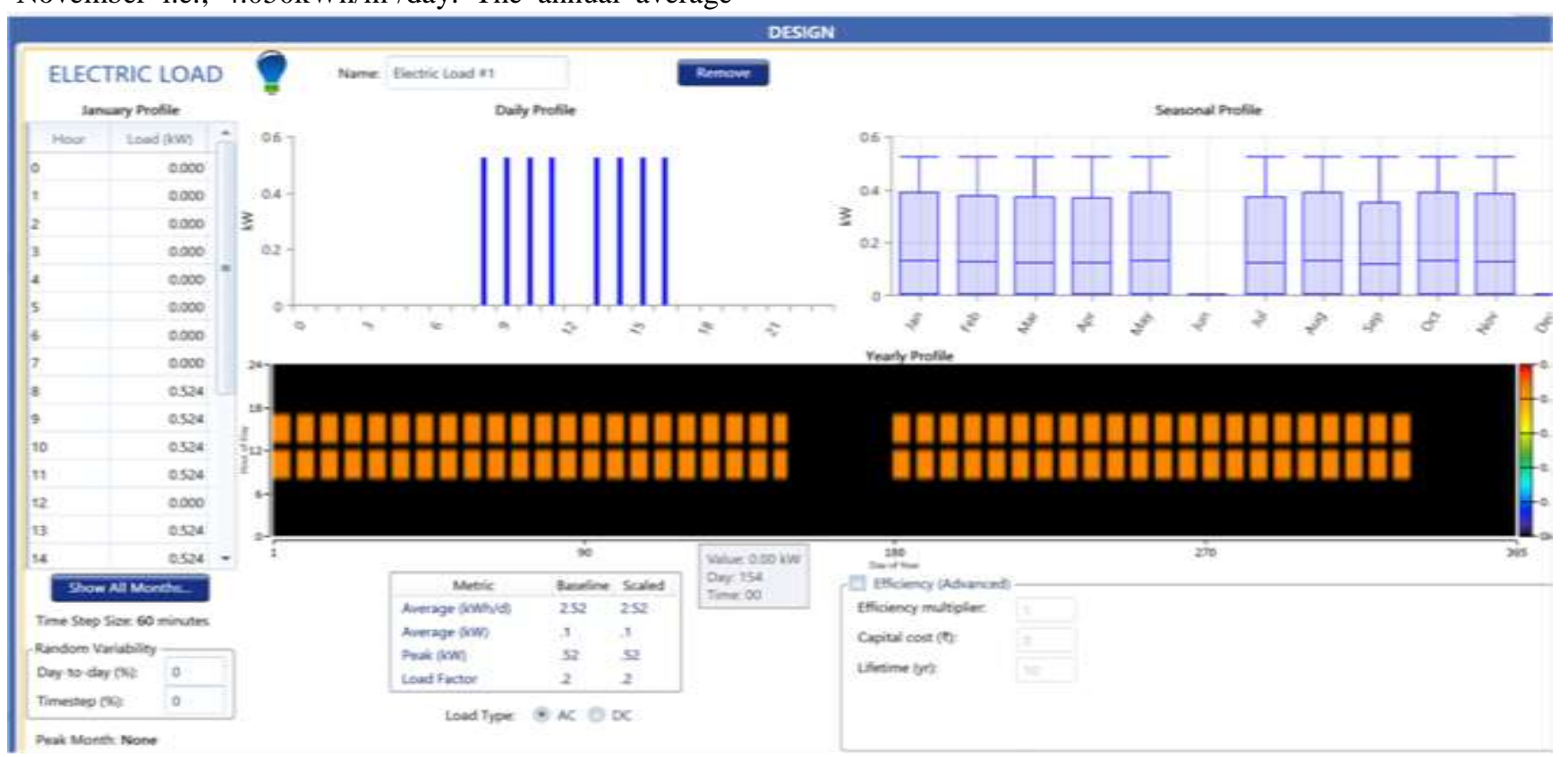

Fig 14.Seasonal,yearly and Daily Load profile of the Lab 


\begin{tabular}{|c|c|c|c|c|c|c|c|c|c|c|c|c|}
\hline \multicolumn{13}{|c|}{ Weekdays } \\
\hline Hour & Jamuary & February & March & Apral & Mar & June & suly & August & September & October & November & December \\
\hline 0 & 0.000 & 0.000 & 0.000 & 0.000 & 0.000 & 0.000 & 0.000 & 0.000 & 0.000 & 0.000 & 0.000 & 0.000 \\
\hline 1 & 0.000 & 0.000 & 0.000 & 0.000 & 0.000 & 0.000 & 0.000 & 0.000 & 0.000 & 0.000 & 0.000 & 0.000 \\
\hline 2 & 0.000 & 0.000 & 0.000 & 0.000 & 0.000 & 0.000 & 0.000 & 0.000 & 0.000 & 0.000 & 0.000 & 0.000 \\
\hline 3 & 0.000 & 0.000 & 0.000 & 0.000 & 0.000 & 0.000 & 0.000 & 0.000 & 0.000 & 0.000 & 0.000 & 0.000 \\
\hline 4 & 0.000 & 0.000 & 0.000 & 0.000 & 0.000 & 0.000 & 0.000 & 0.000 & 0.000 & 0.000 & 0.000 & 0.000 \\
\hline s & 0.000 & 0.000 & 0.000 & 0.000 & 0.000 & 0.000 & 0.000 & 0.000 & 0.000 & 0.000 & 0.000 & 0.000 \\
\hline 6 & 0.000 & 0.000 & 0.000 & 0.000 & 0.000 & 0.000 & 0.000 & 0.000 & 0.000 & 0.000 & 0.000 & 0.000 \\
\hline 7 & 0.000 & 0.000 & 0.000 & 0.000 & 0.000 & 0.000 & 0.000 & 0.000 & 0.000 & 0.000 & 0.000 & 0.000 \\
\hline a & 0.524 & 0.524 & 0.524 & 0.524 & 0.524 & 0.000 & 0.524 & 0.524 & 0.524 & 0.524 & 0.524 & 0.000 \\
\hline 9 & 0.524 & 0.524 & 0.524 & 0.524 & 0.524 & 0.000 & 0.524 & 0.524 & 0.524 & 0.524 & 0.524 & 0.000 \\
\hline 10 & 0.524 & 0.524 & 0.524 & 0.524 & 0.524 & 0.000 & 0.524 & 0.524 & 0.524 & 0.524 & 0.524 & 0.000 \\
\hline 11 & 0.524 & 0.524 & 0.524 & 0.524 & 0.524 & 0.000 & 0.524 & 0.524 & 0.524 & 0.524 & 0.524 & 0.000 \\
\hline 12 & 0.00 & 0.000 & 0.000 & 0.000 & 0.000 & 0.000 & 0.000 & 0.000 & 0.000 & 0.000 & 0.000 & 0.000 \\
\hline 13 & 0.524 & 0.524 & 0.524 & 0.524 & 0.524 & 0.000 & 0.524 & 0.524 & 0.524 & 0.524 & 0.52 .4 & 0.000 \\
\hline 14 & 0.524 & 0.524 & 0.524 & 0.524 & 0.524 & 0.000 & 0.524 & 0.524 & 0.524 & 0.524 & 0.524 & 0.000 \\
\hline is & 0.524 & 0.524 & 0.524 & 0.524 & 0.524 & 0.000 & 0.524 & 0.524 & 0.524 & 0.524 & 0.524 & 0.000 \\
\hline 16 & 0.524 & 0.524 & 0.524 & 0.524 & 0.524 & 0.000 & 0.524 & 0.524 & 0.524 & 0.524 & 0.524 & 0.000 \\
\hline 17 & 0.000 & 0.000 & 0.000 & 0.000 & 0.000 & 0.000 & 0.000 & 0.000 & 0.000 & 0.000 & 0.000 & 0.000 \\
\hline 18 & 0.000 & 0.000 & 0.000 & 0000 & 0.000 & 0.000 & 0.000 & 0.000 & 0.000 & 0.000 & 0.000 & 0.000 \\
\hline 19 & 0.000 & 0.000 & 0.000 & 0.000 & 0.000 & 0.000 & 0.000 & 0.000 & 0.000 & 0.000 & 0.000 & 0.000 \\
\hline 20 & 0.000 & 0.000 & 0.000 & 0.000 & 0.000 & 0.000 & 0.000 & 0.000 & 0.000 & 0.000 & 0.000 & 0.000 \\
\hline 21 & 0.000 & 0.000 & 0.000 & 0.000 & 0.000 & 0.000 & 0.000 & 0.000 & 0.000 & 0.000 & 0.000 & 0.000 \\
\hline 22 & 0.000 & 0.000 & 0.000 & 0.000 & 0.000 & 0.000 & 0.000 & 0.000 & 0.000 & 0.000 & 0.000 & 0.000 \\
\hline 23 & 0.000 & 0.000 & 0.000 & 0.00 & 0.000 & 0.000 & 0.000 & 0.000 & 0.000 & 0.000 & 0.000 & 0.000 \\
\hline
\end{tabular}

Fig 15. Load data for a Year

\subsection{Components}

\section{PV Panel}

Analysis of case B is performed under three different condition, the first condition is by considering on PV source. The PV panel taken is of Generic flat plate type PV. Which is $3 \mathrm{~kW}$ of capacity. The capital cost of the panel is about Rs 90000. The PV panel designed in HOMER is depicted in figure 16 .

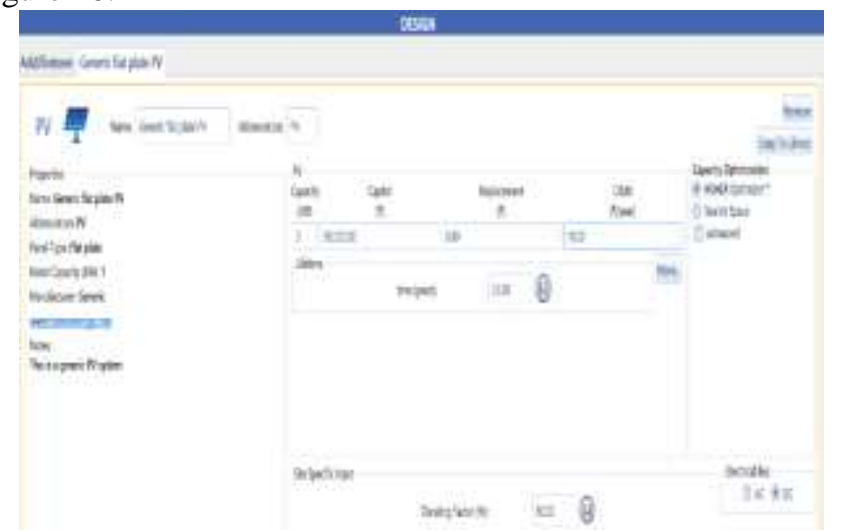

Fig 16.PV panel for Case B

\section{Storage Devices}

Battery acts as a back of energy and also to store excess of energy (charging of battery) so, battery is employed as a storage device. The nominal voltage is considered as $55.5 \mathrm{~V}$ and the rated capacity is $5.7 \mathrm{kWH}$. The number of batteries used is 1 and the initial cost is Rs50000 and the data is picturized in figure 17.

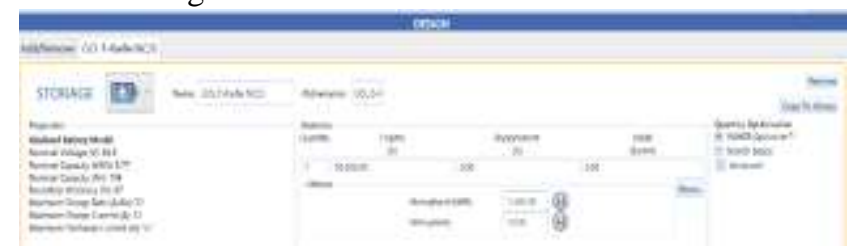

\section{Converter}

The basic function of the converter is to convert AC to DC or vice versa. The capacity of the converter is $3 \mathrm{~kW}$ and the cost is Rs 450000 .

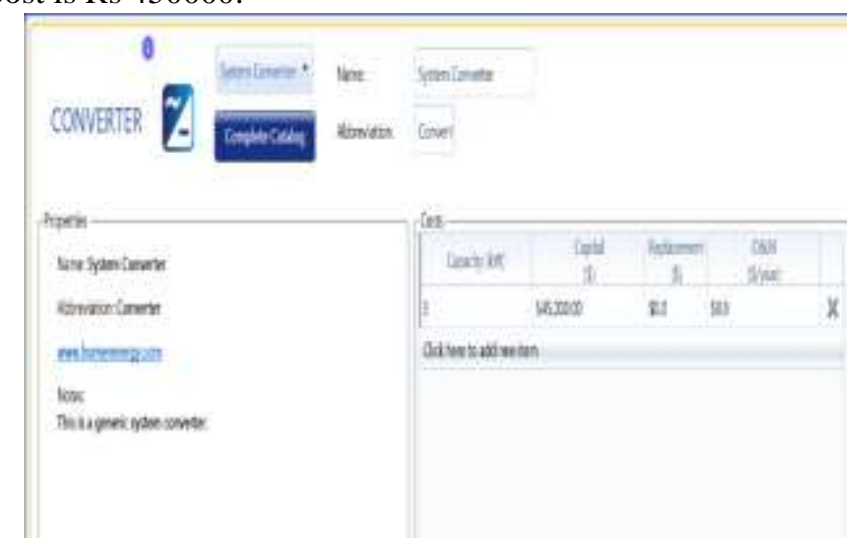

Fig 18. Converter for Case B

4.Schemetic Diagram For Pv System

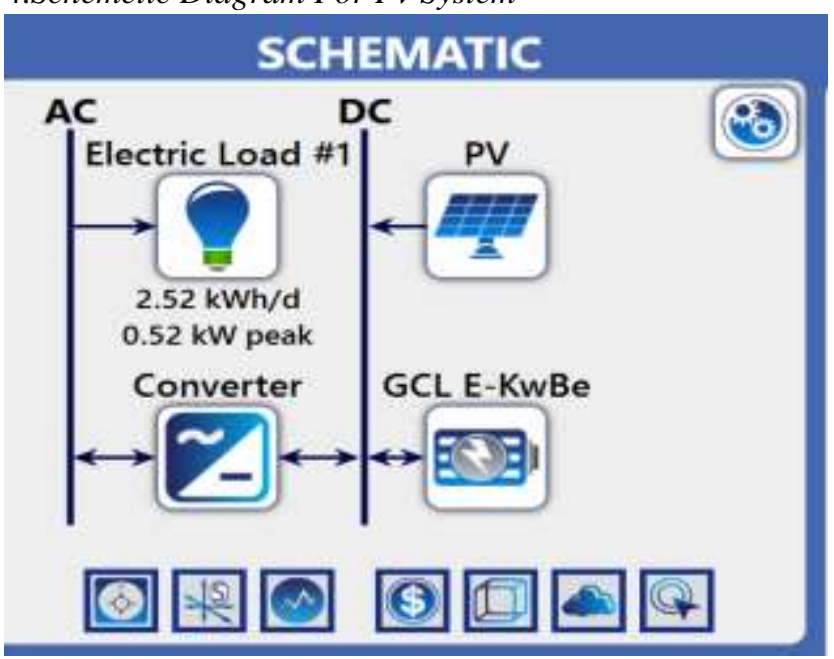

Fig 19.Schematic diagram for Case B

Blue Eyes Intelligence Engineering

\& Sciences Publication 


\section{SIMULATION OF SRMIST LAB (ONLY WIND TURBINE) \& RESULTS}

The second condition considered in case B is to energies the lab using Wind turbine. The wind profile along with the schematic diagram of the wind energy system is explained below.

\subsection{Resource Data}

\section{Wind Resource}

The output of the wind turbine depends on the speed of the wind so maximum wind speed duration yield more generation of power. In the month of June the maximum attainable average speed of wind is $5.170 \mathrm{~ms}$.Similarly the minimum occuring average wind speed is $2.980 \mathrm{~ms}$ all through the month of October. On an average a wind speed of $4.08 \mathrm{~ms}$ is obtained. The key factor in deciding the efficiency of the wind generation system is the blades of rotor. A vital precursor to obtain the design of rotor blade configuration is to choose at least one 2D airfoil segments to frame a smooth rotor blade profile. The design of turbine along with wind speed curve is shown in figure 20 and 21 .

\section{Wind Turbine}

A generic type wind turbin is preffered with its rated capacity to be $3 \mathrm{~kW}$. The cost of wind turbine is Rs 2,26,800.

\section{Wind Turbine Profile Curve}

For the wind turbine a power curve is one that shows how huge the electrical power yield will be for the turbine at various wind speeds. In the event of non fluctuation of wind speed consequently fluctuating too quickly, at that point one may utilize the breeze speed estimations from the anemometer and read the electrical power yield from the wind turbine and plot of the two qualities is made.Figure 22 and 23 depicts wind turbine and its power curve. Figure 24 picturize the schematic diagram with wind turbine alone.

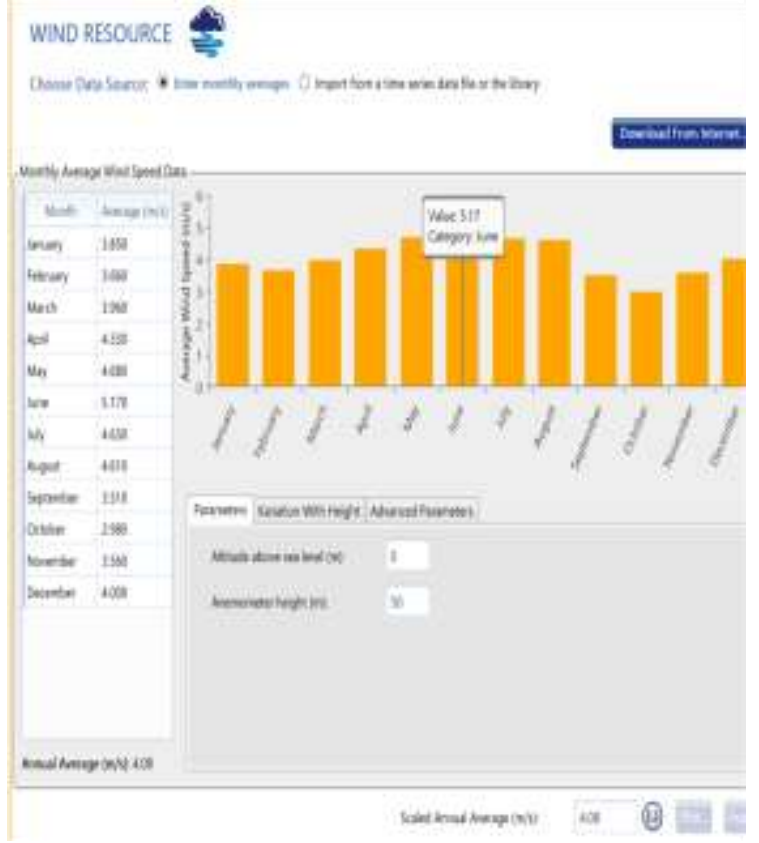

Fig 20 Wind resource design in HOMER

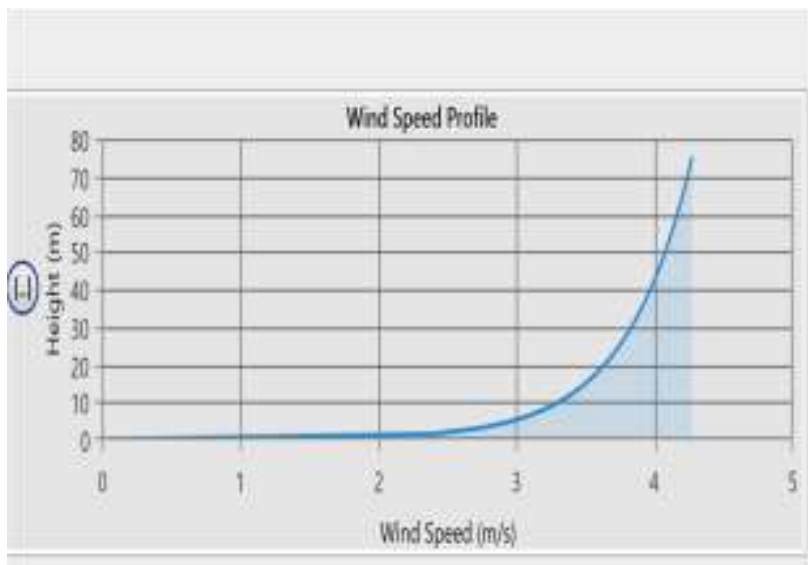

Fig 21. Wind speed

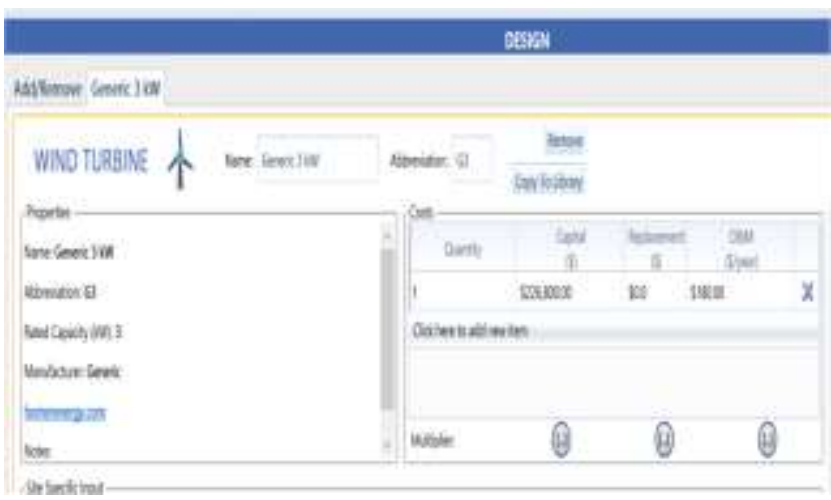

Fig 22. Wind turbine

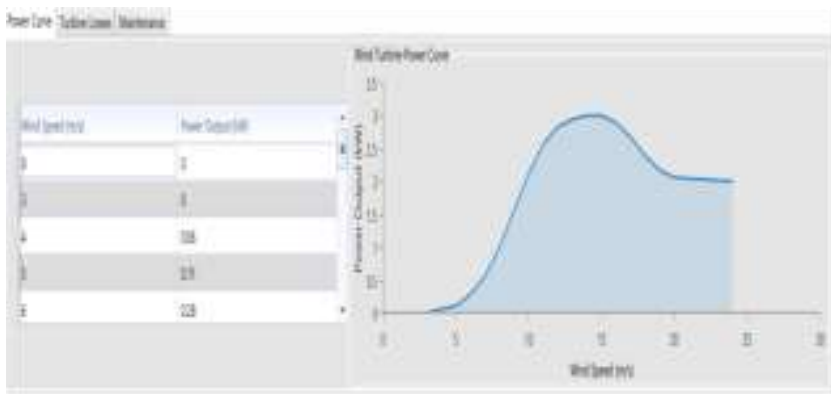

Fig.23 Wind turbine profile curve

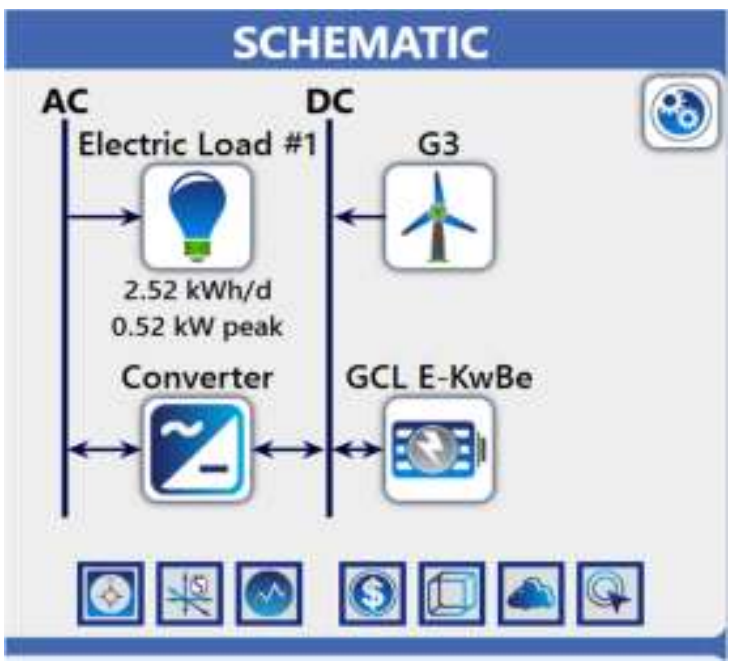

Fig. 24. Schematic with Wind alone

Published By:

Blue Eyes Intelligence Engineering

\& Sciences Publication 


\section{SIMULATION OF SRMIST LAB (PV\&WIND)}

This analysis investigates the options for replacing the present current sources with the renewable hybrid energy source using PV, Wind turbine and both. The generator which is used is Auto size Genset. As we know that generator is a device that converts motive power (mechanical energy) into electrical power for use in an external circuit. Sources of mechanical energy include steam turbines, gas turbines, water turbines, internal combustion engines and even hand cranks. Figure 25 picturizes the schematic diagram of both PV and Wind system serving the total load.

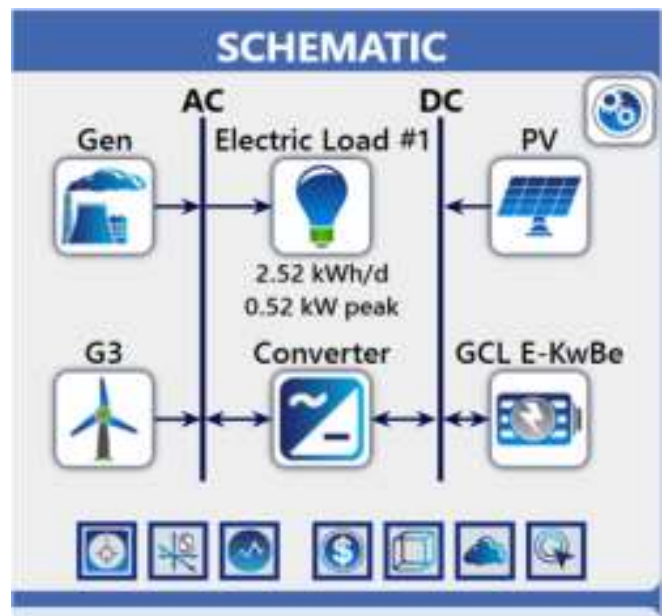

Fig. 25 Schematic diagram with both wind and PV

The operating and maintenance cost,Fuel cost and captical cost along with nominal capacity for PV ,Wind and both PV $\&$ Wind are focused in the figure 26,27 and 28

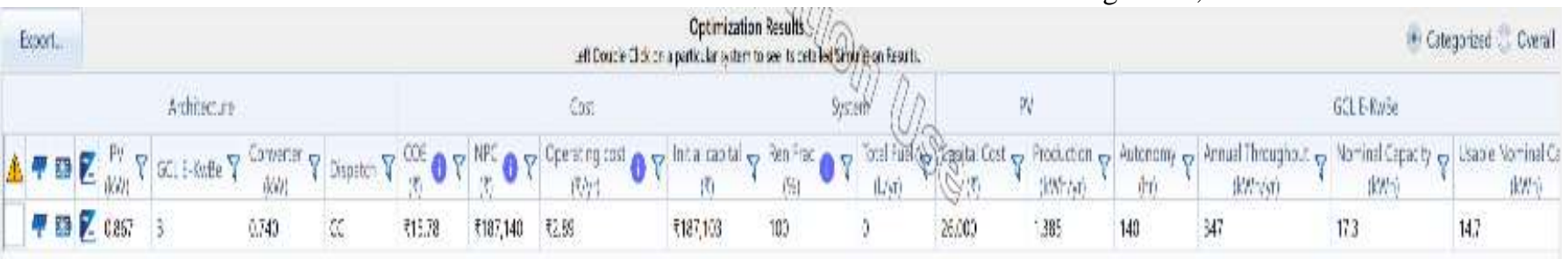

Fig 26: The optimization output with PV alone considered

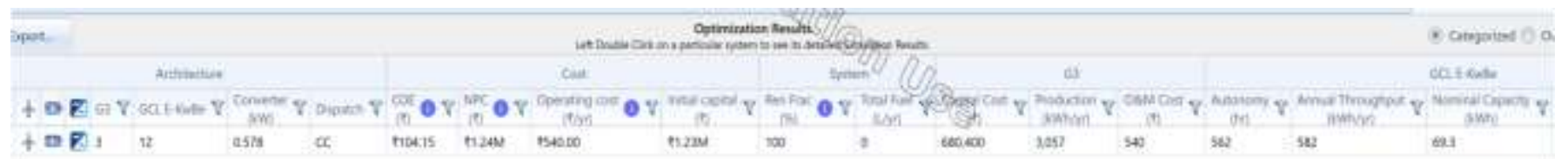

Fig. 27 Optimized result for Wind alone

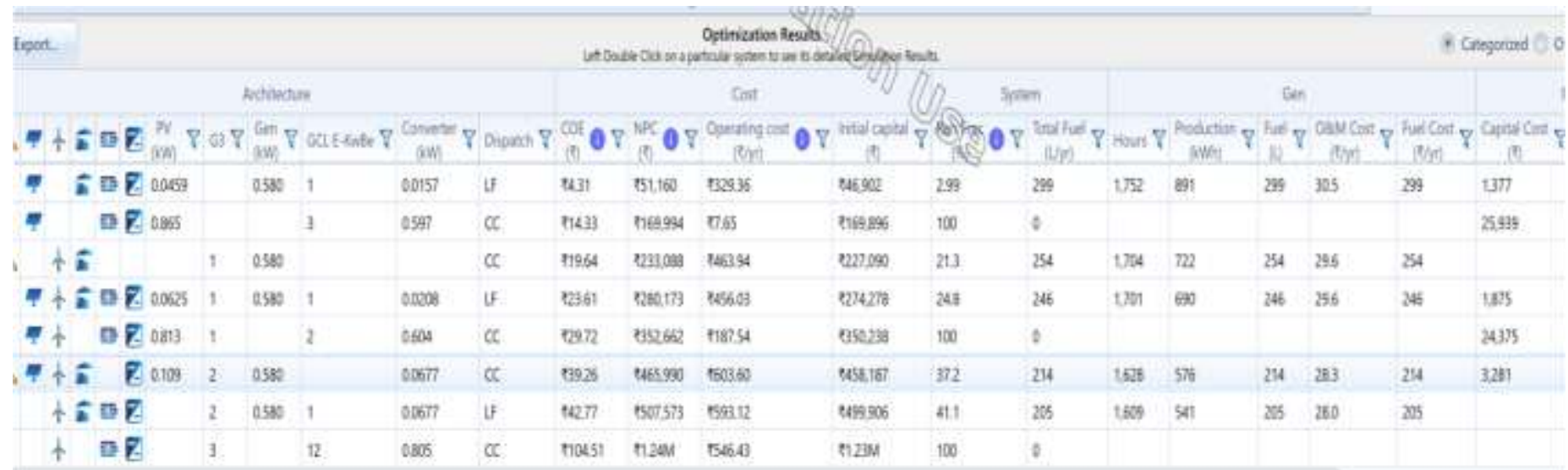

Fig 28. Optimized result for both PV and Wind 


\section{CONCLUSION}

There is a current worldwide requirement for pure and sustainable power sources. Non-renewable energy sources are non-sustainable and require limited assets, which are dwindling due to the expense of generation and causing harm to ecologically system like polluting the surroundings etc. This work concentrated on the usage of SER for electrification of small village or town with the non conventional sources. The analysis and the optimization for this SER system setup is carried out using HOMER. Optimization of environmental cost and the operational cost is implemented using HOMER software by considering PV and Wind turbine as a standalon system. Optimization for various load data are performed along with the comparative analysis of the economic and environmental performance of the system. Optimization performed for Sicud village data concludes that it is feasible to use the PV panel owing to the operating cost getting reduced to 78,129 . SRMIST lab data is considered for three different scheme of operation out of which the best result is obtained when PV panel alone is used to serve the load and the total NPC cost is $2471.80 \$$ which is the most suitable for the site.

\section{REFERENCES}

1. Zobaa A.F., Bansal R.C.: 'Handbook of renewable energy technology' (World Scientific Publishers, Singapore, 2011)

2. Jenkins N., Ekanayake J.B., Strbac G.: 'Distributed generation', IET Renew. Energy Ser., 2010, 1, pp. 1-20.

3. Salehin S., Ferdaous M.T., Chowdhury R.M., et al., 'Assessment of renewable energy systems combining techno-economic optimization with energy scenario analysis', Energy, 2016, 112, pp. 729-741.

4. J. F. Manwel, J. G. McGowan, U. Abdulwahid, "Simplified Performance model for Hybrid Wind-diesel System" Renewable Energy Laboratory, MA, USA.

5. K.R. Ajao, O.A.Oladosu \& O.T. Popoola Karnik, "Using HOMER Power Optimization Software for cost-benefit analysis of Hybrid-Solar power generation

6. O. Erdinc, and M. Uzunoglu, "Optimum design of hybrid renewable energy systems: Overview of different approaches," Renewable and Sustainable Energy Reviews, vol. 16, pp. 1412-1425, 2012.

7. NASA, available at http://eosweb.larc.nasa.gov

8. Alam, S.M.S.U., Rahman, M.H.: Use of Green Energy Instead of IPS to Lessen Energy Crisis in Bangladesh. In: 2nd International Conference on Green Energy and Technology, pp. 83-86, September 2014.

9. Lal, D.K., Dash, B.B., Akella, A.K.: Optimization of PV/Wind/Micro-Hydro/Diesel Hybrid Power System in HOMER for the Study Area. International Journal on Electrical Engineering and Informatics 3(3), 307-325 (2011).

10. Zubair A , Tanvir A.A., Hasan, M.M.: Off-grid hybrid energy system incorporating renewable energy for a remote coastal area of Bangladesh. In: Proceedings of the Global Engineering, Science and Technology Conference, Dhaka, Bangladesh, December 28-29, 2012.

11. Olly Roy Chowdry et al.,"Optimization of hybrid renewable energy system using Homer ", Advances in computer science and ubiquitous computing, Springer, LNEE Vol.373, December 2015.

12. VikasKhare, SavitaNema and PrashantBaredar, "Optimisation of the hybrid renewable energy system by HOMER, PSO and CPSO for the study area", International Journal of Sustainable Energy, Taylor and
Francis ,volume 36, 2017

13. Rashid Al Badwawi et al., "AReview of Hybrid Solar PV and Wind energy System," Journal of smart science , Taylor and Francis ,vol.3, 2016.

14. Norat Mal Swarnkar et al.," An application of HOMER Pro in optimization of hybrid energy system for electrification of technical institute"ICEETS, IEE explore, 2016. 